Appointments to these posts are made at District Health Authority level.

\section{Suitability of posts}

Posts structured in this way for the purposes of further general clinical/professional training are suitable for those planning a career in many specialties provided the post has received appropriate recognition from the relevant specialist Royal College or Faculty. When approved by the Royal College of Psychiatrists, they can provide essential experience for those planning a career in psychiatry or wishing to explore that possibility. Other posts are specifically linked into vocational training programmes for those planning to enter general practice.

\section{Acknowledgement}

This document has been considered by the Psychiatric Sub-Committee of the Regional Postgraduate Medical Committee of the South West Thames Regional Health Authority and I wish to express my appreciation for the helpful suggestions that led to further modifications of the text at that stage.

\section{References}

CRISP, A. H. (1989) The senior house officer (SHO) grade service and education. Postgraduate Medical Journal, 65, 851-857.

Department of Health and Social Security (1987) Hospital Medical Staffing: Achieving a Balance. The "Plan for Action" in brief. A digest of the report issued in October 1987 on behalf of the UK Health Departments, the Joint Consultants Committee, and Chairmen of Regional Health Authorities. JC/2483a/1.

General Medical Council, Education Committee (1987a) Recommendations on the Training of Specialists. October 1987.

- (1987b) Recommendations on General Clinical Training. October 1987.

The Learning of Communication Skills and Psychotherapy by Doctors Training in Psychiatry and Preparing for Entry into Higher Specialist Training, South West Thames RHA (1987) Report of a Working Party set up by the Psychiatric Sub-Committee of the Regional Postgraduate Medical Committee and adopted by the Region.

\title{
Psychiatric training at the Maudsley Hospital: a survey of junior psychiatrists' experiences
}

\author{
Thomas A. FaHy, Lecturer in Psychiatry (correspondence); and Barbara Beats, \\ Lecturer in Psychiatry, Institute of Psychiatry, De Crespigny Park, London SE5 8AF
}

A majority of psychiatrists embark on their careers by entering an $\mathrm{SHO} /$ registrar rotation where they can expect to receive a broad based training in the principles and practice of their chosen specialty. These posts should provide the trainee with an opportunity to observe and emulate high standards of clinical care as well as fostering academic interests and research skills. The Royal College of Psychiatrists recognises the importance of these years by monitoring the standard of posts and by examining trainees at the end of this period.
Walton (1986) has suggested a comprehensive list of goals for trainees and describes how it is possible to achieve them within the framework of three years of general professional training. If the aims of training are made specific, this will aid teachers and trainees by setting goals and allowing assessment by examination and feedback. Trainees have an important role to play in formulating objectives for training by telling their educators what they want and monitoring and reporting on the quality of training which they receive. Indeed Creed \& Murray (1981) credit 
trainees with being more influential in bringing about improvements in general psychiatric training than their teachers. For example, at a time of considerable change in the rules governing professional examinations in psychiatry, trainees made highly effective contributions to the debate (Clare, 1972; O'Farrell, 1973; Creed, 1980).

One method of clarifying trainees' opinions about the quality of their training is by surveying current and recently completed trainees, as was done at the Maudsley Hospital in 1974 by Jeffreys \& Murray (1976) and in 1977 by Creed \& Murray (1981). These authors recommend that the views of trainees should be carefully and systematically monitored so that training programmes can be critically assessed by the consumer and appropriate alterations can be made where possible. Such a system complements the assessment of education by examination alone and allows the trainees' viewpoint to be represented to those in charge of training at a local and a national level. Since the survey by Creed \& Murray, no similar survey results have been published. The intervening time has been an eventful one for psychiatry and it was decided that a further assessment of trainees' views was opportune. In addition to canvassing the opinions of junior psychiatrists on the quality of individual posts, the study was also concerned to establish which factors were most significant in determining whether or not the trainee considered a post to be worthwhile.

\section{The study}

The Bethlem Royal and Maudsley hospital psychiatry training scheme is the largest in the UK. At the time of this survey a total of 60 SHO and registrar posts were based in 43 units. The majority of trainees enter a $3 \frac{1}{2}$ year rotation through general adult psychiatry and a variety of specialist units. The hospital is closely affliliated with the Institute of Psychiatry, which provides teaching and research facilities for junior doctors. There is a comprehensive seminar based academic programme for junior doctors who are expected to attend at least four hours teaching weekly. The background of trainees, their training at the Maudsley and their subsequent professional careers have been well described in previous studies (Toone et al, 1979; Russell, 1972; Davies \& Stein, 1963).

In 1988 a questionnaire was dispatched to SHOs and registrars at the hospital. The questionnaire sought the trainees' opinions about their previous two posts on the rotation. Those who had just finished their first job on the rotation returned only one questionnaire and those who were entering their first posts did not receive a questionnaire. Seventynine questionnaires were sent out and 69 were returned $(87 \%)$ giving information about 40 units.
In the first part of the questionnaire subjects were asked to rate, on a semantic differential scale, their views on overall job satisfaction, consultant supervision, multidisciplinary team involvement in the unit, the orientation of the clinical team (biological and eclectic), quality of patient care on the unit and personal workload during the post. Categorical responses were also used, corresponding with those used in previous questionnaires (Jeffreys \& Murray, 1976; Creed \& Murray, 1981).

\section{Findings}

Trainees rated the vast majority of jobs as 'good' or better and reported a high proportion of jobs provided good quality consultant supervision of junior staff. Trainees also viewed the quality of care provided by most of the clinical teams to be of a high standard, a finding which had not altered since the 1974 and 1977 surveys. Although the workload in the majority of posts was rated as 'about right', more jobs were rated as 'heavy' $(26 \%)$ and 'light' $(26 \%)$ than in previous surveys.

The amount of multidisciplinary team involvement varied a great deal between jobs, some posts such as psychotherapy having little or none and others, such as general adult and child psychiatry posts having a greater commitment. There was little overall change in the amount of multidisciplinary involvement since earlier surveys. Enquiries about the orientation of clinical teams revealed that $9 \%$ were predominantly biologically orientated, $15 \%$ were 'not at all' biologically orientated and $53 \%$ were 'moderately' biologically oriented. Only $23 \%$ of teams were seen to be predominantly 'eclectic' in their orientation.

A minority of trainees received direct teaching from their consultant $(39 \%)$ or senior registrar $(41 \%)$ outside of clinical supervision. Seventy-seven per cent of trainees received useful feedback from their consultants at the end of their jobs, in comparison with $59 \%$ in 1977 and $56 \%$ in 1974.

A disquietingly large proportion of subjects (35\%) reported that they received no encouragement from their consultants to engage in research. However this was a major improvement on previous surveys, where $64 \%$ (1974) and $73 \%$ (1977) of respondents had received no such encouragement. In the current study $9 \%$ of subjects had been 'strongly encouraged' by their consultants to participate in research projects.

A minority of trainees were always able to take a half-day away from their clinical duties every week to attend teaching $(26 \%)$ or engage in research $(30 \%)$. Many were able to take time off on some occasions ( $55 \%$ and $26 \%$ respectively) but a sizeable minority were 'never' able to take this time away from their 
ward duties, with $22 \%$ 'never' able to attend teaching and $44 \%$ with no time free for research.

Subjects were also questioned about the degree to which posts were 'biological' or 'eclectic' in orientation. The results revealed that few posts rejected an eclectic approach or were of predominantly biological orientation.

In an attempt to evaluate what components of a post are viewed by trainees as the most important, the scores on individual items from the questionnaire were correlated with scores on 'overall value of jobs'. High job satisfaction significantly correlated with close supervision of the registrar's workload by the consultant $(0.51, P<0.001)$, a high score for the post on 'eclectic' orientation $(0.34, P<0.01)$ and high quality of patient care in the unit $(0.65, P<0.001)$. There was no significant correlation between job satisfaction and greater workload, multidisciplinary involvement or biological orientation.

\section{Comment}

One of the most satisfying and succinct descriptions of the ideal psychiatry training post was offered by Clare (1972), then a trainee, who suggested that the junior doctor should find himself "studying and working in an intimate training relationship with his instructor and his peers, in an atmosphere which encourages his contributing ideas to others as well as learning from them, in a milieu in which he can test his skills under supervision and synthesise that which he draws from his clinical exposure, from lectures, tutorials, seminars and the laboratory. He should have an adequate but not excessive caseload, with time to discuss his cases." The majority of the posts surveyed in this study received complimentary reports and rated highly on many of the factors referred to by Clare. More than $90 \%$ of jobs were highly valued for the overall experience provided for the trainee. A higher proportion received 'excellent' ratings than in earlier surveys and the quality of patient care was seen as high in most units.

During their first years in psychiatry, trainees face a difficult and potentially stressful task in adjusting to a great change in role and responsibilities. Walton (1986) identifies the cause of adjustment problems as due to the poorly defined division of labour within the multidisciplinary team, the need to tolerate high degrees of diagnostic uncertainty and the complexity and poignancy of many psychiatric problems. During these first years it is therefore not surprising that trainees report that close supervision from the consultant is the most important factor contributing to overall job satisfaction. A similar finding has been reported in an American survey of psychiatric residents, where close supervision of clinical work and accessibility to other staff were highly desired (Kardener et al, 1970). It was reassuring to find that
$75 \%$ of trainees received a high standard of direct clinical supervision. This type of supervision appears to have less to do with academic teaching than with accessibility to the consultant and close monitoring of patient management.

It was also encouraging to find that $74 \%$ of consultants gave useful feedback to trainees about their performances at the end of posts, a major improvement on previous survey reports. However only $30 \%$ received advice in the middle of the job, when it may have been of greater benefit.

One of the undoubted strengths of the Maudsley training programme is the comprehensive seminar based teaching programme, but $22 \%$ of respondents were never able to take regular half-days away from clinical duties to attend teaching and only $26 \%$ were always able to attend. Although we did not ask subjects to detail why they had been unable to attend, it was noted that more than $20 \%$ of all respondents rated their workload to be too heavy and $44 \%$ of these were 'never' able to attend teaching; only $11 \%$ were always able to attend. Trainees in busy posts were also less likely to receive encouragement from their consultants to do research than those in less busy posts (in $56 \%$ of very busy posts research was ignored or discouraged in contrast with $35 \%$ of all posts). They were also less likely to have time available for research ( $56 \%$ never had a weekly half-day for research and $22 \%$ were able to take one always).

The acquisition of research skills is advocated as a valuable experience for psychiatrists in training and sanctioned by the Royal College of Psychiatrists as a valid part of general professional and higher training. A satisfactory training post should encourage research and permit the trainee to devote a proportion of his time to working under supervision on a research project. Walton (1986) suggests that encouragement from the consultant and participation in collaborative research work may be the best method of generating an interest in research among trainees. Previous findings suggested that consultants often failed in their responsibility to junior staff to promote and facilitate research work (Jeffreys \& Murray, 1976; Creed \& Murray, 1981). These studies were conducted at a time when psychiatric research in Britain was thought by some to have lost its 'elusive impetus' (Lancet, 1976). This study indicates that there has been a large increase in the number of trainees who are being encouraged by their consultants to conduct research. It will be of interest in the future to assess how this renewed enthusiasm translates into productive effort.

It is easier to publish lists of objectives for psychiatric trainees than it is to detail how these objectives should be met. Any group which decides to revise training objectives should also represent the views of trainees, which can easily be established through surveys like this one. This study suggests that broadly 
based eclectic programmes of clinical experience with close contact and supervision from senior staff are the ingredients which the trainee sees as essential to a good training. A strong academic programme with promotion and facilitation of research is also important. Each of these items demands the close attention of senior staff, and it would seem appropriate that directives to juniors about the standards which they must meet in order to fully qualify as a psychiatrist should be accompanied by equally detailed objectives for trainers detailing their responsibilities.

\section{Acknowledgement}

We are grateful to Professor Robin Murray.

\section{References}

CREED, F. (1980) Raising standards in psychiatry. Bulletin of the Royal College of Psychiatrists, 38-41.

\& MuRRAY, R. M. (1981) The teaching of clinical skills at a postgraduate hospital. Psychological Medicine, 11, 391-399.
Clare, A. W. (1972) Training of psychiatrists. Lancet, ii, 753-756.

Davies, D. L. \& Stein, L. (1963) What becomes of Maudsley registrars? Proceedings of the Royal Society of Medicine, 56, 115-119.

Jefrefeys, P. M. \& MurRaY, R. M. (1976) Trainees' assessment of vocational training in psychiatry: a pilot study at the Maudsley Hospital. Medical Education, 10, 52-55.

KARDener, S. H., Fuller, M., Mesh, I. N. \& Forgy, E. W. (1970) The trainees' viewpoint of psychiatry residency. American Journal of Psychiatry, 126, 1132-1138.

Lancet (1976) A Wellcome boost, 11, 29-30.

O'FarRell, P. (1973) New fences over old courses. British Journal of Medical Education, 7, 266-270.

Russell, G. F. M. (1972) Postgraduate education in psychiatry and its administrations: the example of the Maudsley Hospital. British Journal of Medical Education, 6, 13-15.

Toone, B. K., Murray, R. M., Clare, A., Creed, F. H. \& SMITH, A. (1979) Psychiatrists' models of mental illness and their backgrounds. Psychological Medicine, 9, 165-178.

Walton, H. (1986) Education and Training in Psychiatry. London: King's Fund.

\section{Computers in psychiatry}

\section{Field data capture}

\section{A. J. D. Macdonald, Head of Section of Psychogeriatrics; and A. Simpson, Research Registrar, Section of Psychogeriatrics, Department of Psychiatry, UMDS (Guy's Campus) Guy's Hospital, London Bridge, London SEl (Present address: Senior Registrar in Psychiatry, Tone Vale Hospital, Taunton, Somerset)}

The process of psychiatric research, as distinct from its content, has been the subject of little comment. Central to present-day techniques are the use of questionnaires and more or less structured interviews. Pre-coded data are preferred, and even if there are few cases in any one study, the quantity of data collected for each usually compensates for this and justifies computer analysis, using statistical packages such as SPSS*. The days of punched cards have passed (only in the last eight years in one centre of excellence), so at least one of the error-prone steps (transfer of data from paper schedules by cardpuncher) has been abolished, but the major chore is still this process, albeit direct to magnetic media (floppy or hard disk).

For many years, researchers in botanical and ecological research have used small, battery-powered data entry and storage devices (computers or even calculators) in field studies (e.g. Stephenson et al, 1976). Data are entered at the point of observation, and later transferred electronically to computer for permanent storage and analysis. The advantages 